\title{
VIHARA DAN PLURALISME PADA MASA JAWA KUNA ABAD VIII - XI MASEHI (Tinjauan Data Prasasti) ${ }^{1}$
}

\author{
VIHARA AND PLURALISM IN ANCIENT JAVA, $8^{\mathrm{TH}}-11^{\mathrm{TH}}$ \\ AD. (Study on Inscriptions)
}

\author{
Agni Sesaria Mochtar \\ Balai Arkeologi Yogyakarta \\ agnimochtar@yahoo.co.id
}

\begin{abstract}
The era of reformation in Indonesia was supposedly articulated with the pluralism of the society. Sadly, many cases regarding religious and ethnic conflicts pronounced the opposite, whereas pluralism and religious tolerance were two of the main characters of the nation since the days of the ancestors. The legacy of those two characters is actually able to be observed through cultural heritage, as a messenger from the past. This study examines one aspect of the practice of religious tolerance, which recorded in the ancient inscriptions from 8th to 11th AD., which selected through purposive sampling procedure. The aforementioned aspect was regarding the important role of ancient vihära as a symbol of religious tolerance in society. Such role was the impact of its functions, which are different with today's modern function. This information on the function and role of the vihāra in ancient Java is provided to support modern Indonesian society to understand their material cultural heritage.
\end{abstract}

Keywords: vihāra, ancient Java, inscription

\begin{abstract}
ABSTRAK
Semangat pluralisme yang didengungkan sebagai nafas era reformasi pada kenyataannya justru berbanding terbalik dengan munculnya konflik-konflik agama dan etnis di beberapa daerah di Indonesia. Padahal, pluralisme dan toleransi antar umat beragama telah menjadi karakter bangsa ini sejak masa nenek moyang. Pelajaran tentang toleransi tersebut sesungguhnya dapat diperoleh melalui pemahaman tentang tinggalan budaya yang sebenarnya merupakan pembawa pesan dari masa lalu. Penelitian ini menelusuri bentuk-bentuk toleransi beragama yang terekam di dalam prasasti-prasasti masa Jawa Kuna dari abad VIII-XI M. Berdasarkan sumber prasasti yang dipilih dengan teknik purposive sampling, diperoleh gambaran tentang vihāra sebagai salah satu institusi yang memiliki peran penting sebagai simbol toleransi beragama dalam masyarakat. Hal tersebut tidak terlepas dari fungsi vihāra di dalam masyarakat pada masa tersebut, yang berbeda dengan pemahaman masyarakat modern tentang fungsinya saat ini. Penyajian informasi tentang fungsi dan peran vihāra pada masa Jawa Kuna merupakan salah satu upaya agar masyarakat modern lebih memahami pentingnya tinggalan budaya materi warisan nenek moyang kita.
\end{abstract}

Kata kunci: vihāra, Jawa Kuna, prasasti.

Tanggal masuk : 12 Maret 2015

Tanggal diterima : 02 November 2015

${ }^{1}$ Artikel ini disusun berdasarkan bagian kecil dari skripsi sarjana Jurusan Arkeologi Fakultas IImu Budaya Universitas Gadjah Mada (2009) yang telah direvisi dengan referensi-referensi baru. 


\section{PENDAHULUAN}

Berbagai kasus kekerasan terhadap suatu umat beragama tertentu oleh umat beragama lainnya hingga saat ini masih sering ditemui dalam masyarakat Indonesia (Sudjangi 2002; Tim Puslitbang Kehidupan Beragama 2006; Tim Peneliti 2001). Toleransi beragama nampaknya masih terbatas pada bagian dari semboyan Bhinneka Tunggal Ika, tanpa dihayati secara menyeluruh dalam kehidupan seharihari. Kemajemukan bangsa ini belum sepenuhnya dipandang sebagai sebuah kekayaan bersama, justru seringkali menjadi topik sensitif yang mudah untuk diprovokasi menjadi konflik. Kondisi tersebut salah satunya dikarenakan belum banyak masyarakat modern yang menghargai sejarah panjang bangsa ini. Padahal, sejarah bangsa merupakan faktor penting pembentuk jati diri bangsa Indonesia yang mampu menunjukkan ciri khas kekuatan dan keunikan kita di antara bangsa-bangsa lain. Kurangnya pemahaman terhadap sejarah menjadikan banyak anggota masyarakat cenderung untuk mengaplikasikan pola-pola pemikiran modern yang belum tentu sesuai dengan konteks kebudayaan Indonesia.

Kurangnya apresiasi terhadap sejarah bangsa salah satunya ditunjukkan dengan masih sedikitnya minat masyarakat luas terhadap tinggalan-tinggalan budaya materi dari masa lampau. Berbagai tinggalan budaya materi sejauh ini masih sebatas dijadikan objek wisata minat khusus. Meskipun ketertarikan masyarakat untuk berwisata budaya merupakan langkah awal yang baik untuk menumbuhkan kecintaan terhadap sejarah bangsa, masih diperlukan pemahaman yang lebih mendalam untuk menggali pokokpokok pelajaran penting yang diwariskan nenek moyang bangsa Indonesia melalui tinggalan-tinggalan budaya materi tersebut.

Hal ini juga diperparah dengan kurangnya publikasi tentang berbagai hasil penelitian arkeologi sehingga masyarakat kesulitan untuk memperoleh sumber-sumber informasi yang dapat membantu mereka dalam memahami tinggalan budayanya secara lebih mendalam. Publikasi yang ada dari beragai hasil penelitian pun masih didominasi oleh literatur berbahasa asing. Tentunya hal ini sedikit banyak memberikan hambatan pada keluasan distribusi informasi kepada masyarakat.

Salah satu agama tertua di Indonesia adalah agama Buddha, yang saat ini justru menjadi agama minoritas. Agama Buddha dalam beberapa tahun terakhir ini telah menjadi perhatian banyak pihak karena perayaan hari raya Waisak yang dilaksanakan dengan megah setiap tahunnya di Candi Borobudur. Peristiwa tersebut selalu menyedot kedatangan pengunjung dalam jumlah besar dari berbagai lapisan dan golongan masyarakat. Peristiwa itu seolah dapat menjadi sarana untuk membina toleransi antar umat beragama. Akan tetapi, tetap saja terjadi tindak-tindak kekerasan terhadap para umat Buddha. Peristiwa pemboman vihāra Ekayana di Jakarta pada tahun 2013 (Kompas.com 2013) menjadi salah satu contohnya. Lebih mengejutkan lagi ketika diketahui ada rencana untuk meledakkan sejumlah vihāra lainnya di Indonesia oleh kelompok teroris yang mengatasnamakan agama tertentu (Kompas.com 2014). Potensi terwujudnya toleransi beragama yang ditunjukkan dalam perayaan hari raya Waisak tersebut sebenarnya dapat dirunut hingga 
jauh ke belakang melalui kajian terhadap tinggalan-tinggalan budaya materi.

Pada masa Jawa Kuna vihāra memiliki peran yang penting dalam masyarakat. Selain sebagai pusat beribadatan agama Buddha, vihāra juga menjadi simbol toleransi beragama pada masa tersebut. Beberapa penelitian tentang vihāra masa Jawa Kuna telah dilakukan sebelumnya seperti oleh Pinardi (1984), yang mengemukakan pendapatnya tentang fungsi Situs Ratu Boko sebagai vihāra Buddhis. Pendapat yang sama juga diungkapkan oleh Miksic (1994, 2331), Sundberg (2004, 95-123) dan Degroot (2006, 55-74) yang secara lebih jauh melakukan perbandingan antara Situs Ratu Boko dengan Abhayagirivihāra di Sri Lanka. Akan tetapi, penelitian terhadap tinggalan bangunan vihāra tidak mudah untuk dilakukan karena jumlahnya sangat sedikit. Dalam hal ini kajian prasasti menjadi penting. Beberapa kajian tentang vihāra melalui data prasasti pernah dilakukan oleh Kusen (1989) dan Darmosoetopo (2003). Kusen (1989) membahas dengan detil bihāra i Pikatan dalam kaitannya dengan perubahan status sawah di Wanua Tengah pada masa pemerintahan raja-raja Mataram Kuna abad VIII-X M berdasarkan Prasasti Wanua Tengah III. Akan tetapi, tidak disebutkan vihāra-vihāra lainnya di Jawa. Sementara Darmosoetopo (2003) membahas kaitan antara sima dengan bangunan keagamaan pada abad IX-X M. Di dalam tulisan tersebut vihāra hanya dibahas sebagai salah satu bangunan keagamaan, sehingga pembahasannya tidak mendalam.

Kajian yang disajikan dalam tulisan ini mencakup seluruh prasasti dari masa Jawa Kuna pada abad VIIIXI M yang menyebut kata vihāra, bihāra, maupun wihāra. Penelusuran mendalam tentang fungsi dan peran vihāra dalam masyarakat pada masa tersebut dilakukan dengan metode deskriptif berdasarkan perbandingan dengan berbagai literatur. Melalui kajian ini dapat diperoleh gambaran tentang definisi dan fungsi asli vihāra pada masa Jawa Kuna dan peranan pentingnya bagi toleransi beragama dalam masyarakat serta menginformasikan tentang perkembangan agama Buddha di Indonesia. Hal ini dilakukan agar tercipta pemahaman yang lebih baik dalam masyarakat modern tentang masing-masing agama yang ada di Indonesia sebagai dasar untuk menumbuhkan toleransi beragama yang seutuhnya.

\section{METODE PENELITIAN}

Data yang digunakan dalam kajian ini adalah prasasti, yaitu artefak bertulis dari masa lalu yang dipahatkan pada logam, batu, tanah liat, atau pun kayu (Soetanti 1996, 172). Pembacaan atas isi prasasti dilakukan melalui hasil transkripsi dan transliterasi dari prasasti-prasasti dari masa Jawa Kuna yang telah disusun oleh Christie (2000; 2002; 2004), Sarkar (1972), dan Brandes (1913). Dalam perspektif arkeologi data tersebut termasuk dalam kategori data sekunder karena sudah merupakan kajian atas artefak asli prasasti. Masa Jawa Kuna dipilih karena dianggap menjadi pusat perkembangan kebudayaan yang mendapat pengaruh baik agama Hindu maupun Buddha, sehingga dapat menggambarkan masyarakat yang heterogen. Abad VIII dijadikan batas bawah rentang waktu penelitian karena pada abad-abad sebelumnya sangat sedikit prasasti yang ditemukan. Sementara abad XI dijadikan batas atas karena setelah 
abad tersebut masyarakat Jawa Kuna mulai mengenal bentuk sinkretisme budaya antara Hindu dan Buddha sehingga sulit untuk diperoleh batasan-batasan yang jelas antara agama Hindu dan Buddha.

Prasasti dari masa Jawa Kuna yang telah ditemukan hingga saat ini berjumlah ratusan. Penentuan prasasti yang digunakan sebagai data penelitian ini dilakukan dengan teknik purposive sampling agar diperoleh prasasti yang berkaitan dengan vihāra. Pemilahan dilakukan dengan cara membaca cepat seluruh transkripsi dan transliterasi yang telah disebutkan di atas dan dipilih dengan kriteria menyebut kata vihāra, bihāra, atau wihāra. Perbedaan huruf awal $v, b$, dan $w$ dianggap sebagai gejala fonologi yang tidak mempengaruhi arti kata. Berdasarkan teknik tersebut diperoleh 21 prasasti berbahan batu dan logam yang memenuhi kriteria. Prasasti masa Jawa Kuna masih menggunakan pertanggalan tahun Saka. Konversi pertanggalan ke dalam tahun Masehi mengikuti hasil penghitungan Christie (2000; 2002; 2004) dan Damais (1952). Sementara prasasti-prasasti yang belum masuk dalam daftar keduanya dikonversi dengan cara menambahkan 78 tahun dari angka tahun Saka yang terdapat pada prasasti. Seluruh prasasti yang telah dipilih kemudian diterjemahkan ke dalam bahasa Indonesia. Kutipankutipan yang memuat informasi tentang fungsi dan peran vihāra dianalis dan dibandingkan dengan hasil-hasil penelitian sebelumnya untuk memperoleh gambaran utuh tentang eksistensi vihāra pada masyarakat Jawa Kuna abad VIII - XI M.

\section{HASIL DAN PEMBAHASAN}

\section{Sejarah Agama Buddha di Indonesia}

Agama Buddha awalnya merupakan sebuah filosofi hidup yang muncul pada abad ke-6 SM di daerah Nepal. Filosofi tersebut dicetuskan oleh Śakyamuni Gautama, yang kemudian dikenal sebagai Sang Buddha, setelah berhasil mencapai pencerahan. Filosofi tersebut diajarkan oleh Sang Buddha dalam bentuk dharmma (ajaran Buddha). Inti ajaran dharmma adalah pelepasan diri dari sengsara karena terlahirkan kembali (samsara) dan mencapai tingkat terbebas dari siklus reinkarnasi (nirvāna). Ajaran Sang Buddha tersebut kemudian tersebar luas ke berbagai daerah. Setelah sampai di India filosofi hidup tersebut berkembang, dan kemudian pada sekitar abad I SM berubah menjadi sebuah doktrin religius dan menempatkan Sang Buddha pada posisi dewa seperti dewa-dewa dalam pantheon Hindu (Louis 1995, 17). Para pemeluk agama Buddha terdiri dari golongan agamawan, yaitu para bhiksulbhiksuni dan golongan awam yaitu para upāsaka/upāsika (Robinson dan Johnson 1977, 56). Para bhiksu adalah orang-orang yang meninggalkan masyarakat ramai dan keduniawian, hidup bersama dalam biara, serta menjalankan daçaçila. Para upāsaka/upāsika adalah orangorang yang hidup sebagai anggota masyarakat biasa. Perkumpulan para bhiksu disebut sanigha (Soekmono 1973, 22). Para pemeluk agama Buddha harus memiliki kepercayaan kepada Triratna yang terdiri dari Buddha, Dharmma, dan Sarigha (Robinson dan Johnson 1977, 56).

Agama Buddha datang ke Indonesia pada abad V M (Damais 1995, 85). Pada masa yang kurang 
lebih bersamaan agama Hindu juga masuk ke Indonesia seperti terlihat pada prasasti Kutai dan Ciampea (Griffith 2014, 53). Kedua agama tersebut membawa pengaruh besar terhadap kehidupan masyarakat saat itu, khususnya masyarakat Jawa Kuna. Agama Buddha yang masuk ke Indonesia pertama kali diperkirakan adalah aliran Buddha Hīnayāna yang dibawa oleh bhiksu dari Sri Lanka. Bhiksu dari India datang ke Indonesia pada masa yang lebih kemudian dengan membawa aliran Buddha Mahāyāna.

Bukti tertua keberadaan Buddhisme di Indonesia ditemukan di pantai utara Jawa Barat, yaitu di situs Batujaya yang berupa tsa tsa (Manguin \& Agustijanto 2011, 11318). Tsa tsa adalah votive tablet yang memiliki relief Dhyanibuddha Amitabha. Tsa tsa tersebut diperkirakan berasal dari sekitar abad VI - VII M karena memiliki kesamaan dengan yang ditemukan Dwarawati, Thailand (Indradjaja 2005, 54). Bukti tertua kedua adalah sebuah prasasti batu yang ditemukan di Dusun Tekarik, Kalimantan Barat. Prasasti ini ditemukan di daerah aliran Sungai Kapuas. Prasasti ini bergambar tujuh buah stūpa yang dipahatkan pada sebuah batu besar. Pada setiap stūpa dan di antara stūpa ketiga dan keempat terdapat tulisan mantra Buddhis. Berdasarkan analisis paleografi, prasasti tersebut berasal dari abad VI - VII M (Utomo 2007, 10-11). Bukti tertua ketiga ditemukan di Sulawesi Barat, berupa arca Buddha dari perunggu yang bergaya Amarāvati. Sebelumnya arca ini diperkirakan dari sekitar abad II-V M (Utomo 2007, 12) dan dianggap sebagai artefak bercorak Buddhis tertua di Indonesia, tetapi penelitian terbaru menyebutkan bahwa arca ini tidak lebih tua dari abad VIII M (Guy 2014, 8).
Selain bukti-bukti arkeologis, kedatangan agama Buddha ke Indonesia juga dapat ditelusuri dari beberapa berita Cina. Seorang bhiksu Tionghoa bernama Fa-Hsien menyebutkan bahwa seorang pangeran di Kashmir menjadi bhiksu dan tinggal di Sri Lanka. Sekitar abad $\mathrm{V} M$, pangeran yang telah menjadi bhiksu tersebut pergi ke Cho-p'o. Dengan pertolongan ibu suri seorang raja yang memerintah di Jawa, ia berhasil menyebarkan Buddhisme Hīnayāna dari aliran Mulasarwatiwada-Nikaya

(Kandahjaya 2004, 43). Berita Cina lainnya, ditulis oleh I-tsing, menyebutkan bahwa seorang guru Tionghoa bernama Hwui-Ning datang ke Jawa pada tahun 664/665 M. la tinggal di Jawa selama tiga tahun dan bekerjasama dengan Joh-na-po-t'o-lo (Jnanabadra) menerjemahkan kitab agama Buddha Hinayana. Catatan Itsing juga menceritakan tentang agama Buddha di Kerajaan Sriwijaya yang merupakan pusat kebudayaan, peradaban, dan ilmu pengetahuan agama Buddha aliran Mahāyāna. Bhiksu-bhiksu yang datang ke Sriwijaya mendapat tempat khusus dan sangat dihormati oleh penguasa dan rakyat Sriwijaya. Bhiksu-bhiksu tersebut tinggal dalam waktu yang lama untuk mempelajari agama Buddha, termasuk I-tsing. la mempelajari tata bahasa sanskrta dan menterjemahkan kitab-kitab suci agama Buddha dari bahasa sanskrta ke bahasa Cina (Utomo 2007, 12). Berita Cina yang lain menyebutkan bahwa Dharmapala yang berasal dari Kanci dan mengajar di Universitas Nālandā, juga mengajar Buddha Mahāyāna di Swarnnadwipa. Berita Cina tersebut juga menyebutkan bahwa Dharmapala tiba di Swarnnadwipa lima puluh tahun lebih dulu daripada I-Tsing (Utomo 2007, 13). 


\section{Dinamika Keberadaan Vihāra Pada Masa Jawa Kuna Abad VIII-XI M}

Vihāra saat ini dipahami oleh masyarakat masa kini sebagai tempat peribadatan pemeluk agama Buddha yang identik dengan klenteng. Akan tetapi, agama Buddha sekarang ini telah mengalami percampuran dengan unsur kepercayaan Konghuchu. Vihāra dalam konteks ini berfungsi sebagai pusat kegiatan agama dan kebudayaan. Kegiatan yang diadakan di dalam vihāra adalah berdoa, bermeditasi, dan membaca paritta (Chodron 1995, 44). Namun, jauh sebelum terbentuknya definisi berdasarkan keadaan masa sekarang sebenarnya vihāra memiliki definisi asli yang berbeda. Beberapa ahli telah Akan tetapi, agama Buddha sekarang ini telah mengalami percampuran dengan unsur kepercayaan Konghuchu. Vihāra dalam konteks ini berfungsi sebagai pusat kegiatan agama dan kebudayaan. Kegiatan yang diadakan di dalam vihāra adalah berdoa, bermeditasi, dan membaca paritta (Chodron 1995, 44). Namun, jauh sebelum terbentuknya definisi berdasarkan keadaan masa sekarang sebenarnya vihāra memiliki definisi asli yang berbeda. Beberapa ahli telah mengemukakan pendapat tentang definisi vihāra. Percy Brown dalam Soekmono (1974, 118) menyebutkan, "...the monastery proper, an arragement of appartments for the accomodation of the monks, (is) known as vihāra...". Sejalan dengan Brown, Liebert (1976, 337) juga menyebutkan vihāra sebagai "monastery". Soekmono (1974, 118), berdasarkan prasasti Kalasan, mengartikan vihāra sebagai sebutan untuk keseluruhan gugusan bangunan yang terdiri dari kuil dan asramanya. Zoetmoelder (2004, 1431) mengartikan vihāra sebagai, "biara atau candi, yang aslinya merupakan serambi tempat para pendeta berkumpul atau berjalanjalan". Sementara Kusen $(1989,55)$ mendefinisikan vihāra sebagai "tempat tinggal atau tempat persinggahan para pendeta agama Buddha (bhiksu) dan juga tempat para bhiksu tersebut berkumpul dan mendiskusikan hal-hal yang berhubungan dengan agama". Pertama, agar para bhiksu memiliki tempat yang aman dan damai untuk bermeditasi. Kedua, agar orangorang terpelajar dapat tinggal di sana untuk memperdalam ilmunya (Sankhalia 1934, 29).

Keberadaan vihāra pada masa Jawa Kuna saat ini sulit ditelusuri jejaknya melalui ting galan bangunan monumental karena jumlahnya yang sedikit. Hanya double platform di Kompleks Ratu Boko dan Candi Sari yang masih bisa diamati dengan jelas. Akan tetapi, keberadaan vihāra masih dapat ditelusuri dari prasasti. Pada kurun waktu dari abad VIII hingga abad XI $M$, terdapat 21 prasasti yang menyebutkan tentang vihāra, seperti terlihat pada tabel di bawah ini. 
Tabel 1. Daftar prasasti-prasasti tentang vihāra abad VIII-XI M

\begin{tabular}{|c|c|c|c|c|}
\hline NO & NAMA PRASASTI & TAHUN(M) & NAMA VIHĀRA & DAERAH SĪMA \\
\hline $1 .$. & Kalasan & 778 & Vihāra i Kalasa & Wanua Kalasa \\
\hline 2. & Abhayagirivihāra & 792 & Vihāra Abhayagiri & Tidak disebutkan \\
\hline 3. & Kayumwungan & 824 & Vihāra & Tidak disebutkan \\
\hline 4. & Abhayananda & 826 & Wihāra Abhayananda & Sawaḥ 4 tampaḥ \\
\hline 5. & Kuți & 840 & Kuți & Lmaḥ Waharu \\
\hline 6. & Wayuku & 854 & Wihāra Abhayananda & $\begin{array}{c}\text { Sawah i wanua } \\
\text { Wayuku }\end{array}$ \\
\hline 7. & Wihāra & 874 & Wihāra & Tidak disebutkan \\
\hline 8. & Salimar IV & 880 & Wihāra i Kandang & Tidak disebutkan \\
\hline 9. & Kalirungan & 883 & Wihāra i Kalirungan & Wanua Kalirungan \\
\hline 10. & Munggu Antan & 887 & Wihāra i Gusali & Wanua Munggu Antan \\
\hline 11. & Poh & 905 & $\begin{array}{c}\text { Wihāra waitanning } \\
\text { hawan }\end{array}$ & Wanua Wrang \\
\hline 12. & Palepangan & 906 & Bihāra ing Pahai & Wanua Srāngan \\
\hline 13. & Sangsang & 907 & $\begin{array}{c}\text { Wihāra i Hujung } \\
\text { Galuh }\end{array}$ & Wanua Sangsang \\
\hline 14. & Wukajana & - & Bihāra i Dalinan & $\begin{array}{l}\text { Wanua Wukajana, } \\
\text { Tumpang, Wuru Tlu }\end{array}$ \\
\hline 15. & Guntur & 907 & Wihāra i Garung & Wanua Guntur \\
\hline 16. & Wanua Tengah III & 908 & Bihāra i Pikatan & Sawaḥ i wanuaTngah \\
\hline 17. & Wutit & - & Sang Hyang Wihāra & Wanua Wutit \\
\hline 18. & Piling- Piling & - & Wihāra? & Tidak disebutkan \\
\hline 19. & Wurudu Kidul A & 922 & Wihāra i Halaran & Tidak disebutkan \\
\hline 20. & Hara-Hara & 966 & Sang Hyang Kuți & Sawah \\
\hline 21. & Kelagěn & 1037 & Wihāra & Tidak disebutkan \\
\hline
\end{tabular}

(Sumber : Mochtar 2009, 88)

Berdasarkan informasi tentang vihāra yang disebutkan dalam teksnya, prasasti-prasasti tersebut dibagi dalam tiga kelompok, yaitu:

1. Kelompok prasasti tentang pendirian vihāra dan penetapan sìma vihāra. Prasasti yang termasuk kelompok ini adalah prasasti Kalasan $778 \mathrm{M}$, prasasti Abhayagirivihāra $792 \mathrm{M}$, prasasti Kayumwungan 
(Karang Tengah) $824 \mathrm{M}, \quad$ Buddhisme tersebut, tidak ada prasasti Wayuku $854 \mathrm{M}$, penganut Buddhisme di dalam prasasti Kalirungan 883 M, masyarakat Jawa Kuna. Seperti prasasti Sangsang 907 M, tertulis pada prasasti Wanua Tengah prasasti Wukajana, prasasti III (908 M), vihāra i Pikatan didirikan Wanua Tengah III $908 \mathrm{M}$, dan oleh rahyangta i Hara, adik rahyangta prasasti Hara-Hara 966 M. i Mḍang (Kusen 1989, 69), yang ada Panangkaran. Hal ini memberikan bukti bahwa sebelum Rakai penetapan sìma untuk vihāra. Prasasti yang termasuk kelompok ini adalah prasasti Abhayananda $826 \mathrm{M}$, prasasti Kuți 840 M, prasasti Wihāra $874 \mathrm{M}$, prasasti Munggu Antan $887 \mathrm{M}$, dan prasasti Wutit.

3. Kelompok prasasti yang tidak menyebutkan vihāra sebagai isi pokok, tetapi pada bagian daftar saksi atau daftar pejabat penerima pasěkpasěk disebutkan kata vihāra di dalamnya. Prasasti yang termasuk kelompok ini adalah prasasti Salimar IV 880 M, prasasti Poh $905 \mathrm{M}$, prasasti Palepangan $906 \mathrm{M}$, prasasti Guntur 907 M, prasasti Pilingpiling, prasasti Wurudu Kidul A $922 \mathrm{M}$, dan prasasti Kelagěn $1037 \mathrm{M}$.

Hampir seluruh prasasti yang menyebut kata vihāra dalam kurun VIII-XI M berangka tahun. Dari angka tahun tersebut dapat menunjukkan dinamika keberadaan vihāra pada masa Jawa Kuna abad VIII-XI M. Sebelum abad VIII M, tidak ditemukan prasasti yang menyebut vihāra. Hal ini tampaknya dapat dikaitkan dengan peristiwa sejarah tentang kepindahan Rakai Panangkaran dari penganut Hindu menjadi Buddhis yang terjadi pada abad VIII M. Meskipun demikian, tidak berarti bahwa sebelum kepindahan Rakai Panangkaran ke

Panangkaran sudah ada penganut Buddhisme.

Pada abad VIII M (lihat tabel 1.) terdapat dua prasasti yaitu prasasti Kalasan 778 M, dan prasasti Abhayagirivihāra 792 M yang menyebut keberadaan vihāra. Pada abad IX M terdapat delapan vihāra yang terekam dalam prasasti, yaitu prasasti Kayumwungan $824 \mathrm{M}$, prasasti Abhayananda $826 \mathrm{M}$, prasasti Kuți 840 M, prasasti Wayuku $854 \mathrm{M}$, prasasti Wihāra $874 \mathrm{M}$, prasasti Salimar IV 880 M, prasasti Kalirungan $883 M$, dan prasasti Munggu Antan 887 M. Pada abad X $M$ terdapat sepuluh vihāra yang terekam pada prasasti, yaitu prasasti Poh 905 M, prasasti Palepangan 906 $M$, prasasti Sangsang $907 \mathrm{M}$, prasasti Wukajana (abad $X \quad M$ ), prasasti Wutit (abad X M), prasasti Piling-Piling(abad $X \quad M)$, prasasti Wurudu Kidul A 922 M dan prasasti Hara-Hara 966 M. Pada abad XI M terdapat sebuah vihāra yang terekam pada prasasti, yaitu prasasti Kelagěn 1037 M. Dengan demikian dapat diketahui adanya pertambahan jumlah vihāra pada kurun waktu abad VIII - IX M dari dua ke delapan buah. Pada abad $X \quad M$ jumlah vihāra bertambah menjadi sepuluh buah. Akan tetapi, pada abad XI M jumlah vihāra yang tersebut dalam prasasti mengalami penurunan. Perlu dikemukakan bahwa jumlah vihāra yang diketahui adalah vihāra yang terekam dalam prasasti. Oleh karena itu, tidak ditolak kemungkinan masih 


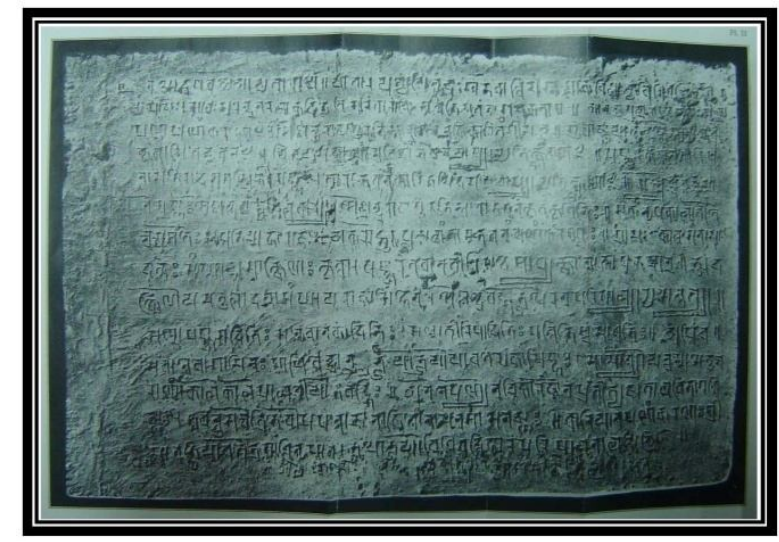

Gambar 1. Prasasti Kalasan 778 M

Sumber: repro Bosch

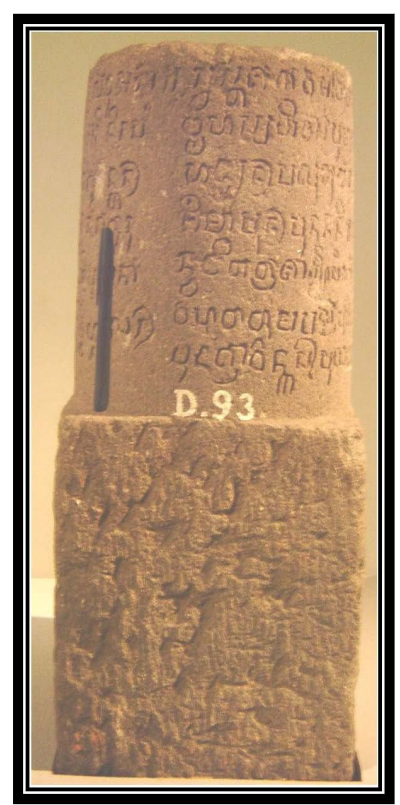

Gambar 2. Prasasti M unggu Antan 887 M , Koleksi M useum Nasional D. 93 Sumber: Dokumentasi penulis, 2008

terdapat vihāra-vihāra lainnya di Jawa yang tidak terekam dalam prasasti.

Dinamika keberadaan vihāra tersebut menunjukkan bahwa puncak keberadaan vihāra pada masa Jawa Kuna terjadi pada abad X $M$, yang ditunjukkan dengan jumlah vihāra yang paling banyak, yaitu sepuluh vihāra. Dengan demikian dapat diasumsikan bahwa jumlah bhiksu paling banyak adalah pada abad $X$ $M$, sehingga dapat disimpulkan pula bahwa Buddhisme di Jawa Kuna mengalami puncak perkembangan pada abad X M. Menarik untuk diperhatikan adalah bahwa data dari prasasti tersebut menunjukkan kondisi yang berbeda dengan penelitian tentang Buddhisme yang 
telah dilakukan sebelumnya. Casparis (1965, 187-191), berdasarkan analisis terhadap isi prasasti Plaosan Lor, mengungkapkan bahwa Buddhisme Mahāyāna mencapai puncak perkembangannya pada pertengahan abad IX M. Demikian pula perkiraan umur candi-candi Buddhis periode Jawa Tengah. Dumarcay dalam Prajudi (1999, 124) menyebutkan bahwa candi-candi Buddhis tersebut seperti Candi Borobudur, Candi Mendut, Candi Pawon, dan Candi Banyunibo, diperkirakan didirikan pada sekitar abad IX M. dapat dirunut melalui sejumlah prasasti tentang vihāra pada masa Jawa Kuna abadVIII-XI M. Menurut beberapa definisi yang telah dikemukakan sebelumnya, vihāra dianggap hanya berfungsi untuk aktivitas religius saja. Hal tersebut diperkuat dengan isi prasasti Kalasan 778 M, Abhayagirivihara 792 M, dan Kayumwungan $824 \quad M$ yang memberikan gambaran tentang peran vihāra sebagai menjadi pusat aktivitas pemujaan dan penyebaran ajaran-ajaran agama Buddha oleh para bhiksu yang terpelajar. Akan tetapi, dalam prasasti jayapattra

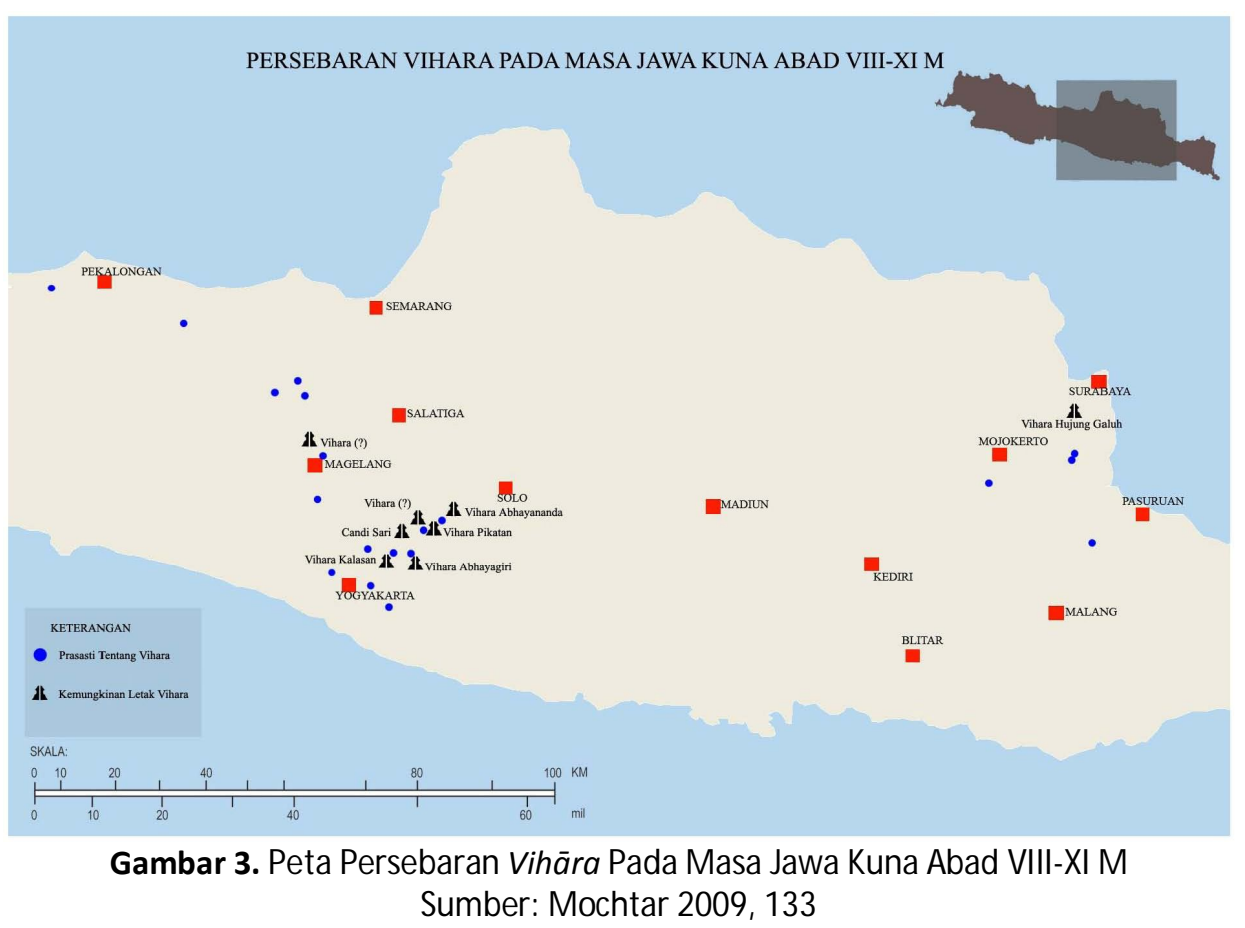

\section{Vihara Sebagai Simbol Toleransi Beragama}

Masyarakat Jawa Kuna merupakan masyarakat plural yang hidup dengan corak kebudayaan Hindu dan Buddha. Kedua agama tersebut, sejauh penelitian yang telah dilakukan hingga kini, dapat berdampingan secara damai sejak abad V M sampai abad XVI M. Toleransi kedua agama tersebut
Wurudu Kidul A 922 M diperoleh informasi bahwa vihāra juga terlibat dalam proses penetapan hukum, yaitu sebagai saksi yang meneguhkan keputusan hukum terhadap seseorang.

Peran vihāra dalam aspek nonreligi masyarakat juga dapat ditelusuri dari daftar raja-raja yang menetapkan simma untuk vihāra atau menganugrahkan hak menetapkan sima untuk vihāra kepada pejabat 
tertentu. Darmosoetopo (2003, 93) mendefinisikan sima sebagai berikut:

"Sima bukan berkaitan dengan hasil tanahnya, melainkan menyangkut pajak dan kewajiban penduduk yang bertempat tinggal di tanah sima. Perubahan yang terjadi ialah bila sebidang tanah telah dijadikan sima, pajak dan kewajiban penduduk yang biasanya diserahkan semuanya kepada raja atau pejabat tinggi kemudian diubah, yaitu sebagian diserahkan kepada bangunan keagamaan yang mendapat tunjangan tanah sima."

Rakal

Raja-raja tersebut terdiri atas Rakai Kayuwangi, Rakai Gurunwangi, dan Rakai Watukura Dyah Balitung. Rakai Panangkaran, Dharmotunggadewa, dan Samaratungga adalah raja-raja yang beragama Buddhis. Prasasti Kalasan $778 \mathrm{M}$, Prasasti Abhaya-girivihāra $792 \mathrm{M}$, dan Prasasti Kayumwungan $824 \mathrm{M}$ merupakan bukti kuat bahwa raja-raja tersebut beragama Buddhis, jadi tidaklah mengherankan apabila mereka mendirikan vihāra Buddhis.

Menurut Prasasti Siwagrha 856

M, Rakai Kayuwangi adalah anak Rakai Pikatan. Oleh karena itu, kemungkinan besar ia beragama Hindu (Kusen 1989, 89). Rakai Gurunwangi merupakan tokoh raja yang sulit identifikasi agamanya karena hanya memerintah kurang dari sebulan dan hanya mengeluarkan satu prasasti (Kusen 1989, 92). Rakai Watukura Dyah Balitung beragama Siwa, sebagaimana ditegaskan dalam gelar pen-tahbisan (abhisekanama) yang disandangnya yaitu sebagai titisan
Siva (rudra murti). Raja-raja yang beragama Hindu tersebut ternyata juga menetapkan sīma untuk vihāra atau menganugrahkan hak menetapkan simma untuk vihāra. Rakai Kayuwangi menetapkan sima untuk vihāra di Kalirungan yang merupakan dharmma Rake Hamēas Pu Tatu. Rakai Watukura Dyah Balitung mengembalikan status sawah di Wanua Tengah sebagai sìma vihāra di Pikatan. la juga menganugrahkan hak menetapkan sima kepada $\mathrm{Pu}$ Layang untuk menetapkan sima bagi vihāra di Hujung Galuh dan di Dalinan.

Alasan para raja Hindu tersebut menetapkan sima untuk sebuah vihāra dapat bervariasi. Kemungkinan, alasan tersebut adalah untuk menunjukkan penghormatan kepada penganut Buddhisme agar dapat melaksanakan pemujaan dengan baik. Namun, tidak ditutup kemungkinannya bahwa terdapat alasan politis yang melatarinya. Seorang raja yang ingin menguasai wilayah yang besar, perlu mengambil simpati dari semua golongan. Apabila raja tersebut, seperti halnya Rakai Kayuwangi dan Rakai Watukura Dyah Balitung, beragama Hindu, maka tidak sulit untuk memperoleh dukungan dari golongan pendeta Hindu. Akan tetapi, diperlukan upaya untuk mendapat dukungan dari golongan rokhaniwan Buddhis yang tidak kalah penting perannya dengan pendeta Hindu. Cara yang ditempuh adalah dengan memberikan anugrah sìma bagi vihāra Buddhis.

$$
\text { Alasan politis yang }
$$

dikemukakan, dilakukan pada masa Rakai Watukura Dyah Balitung, karena ia diperkirakan naik tahta karena perkawinan, bukan karena hak pribadinya. Oleh karena itu, ia membutuhkan legitimasi dari berbagai pihak untuk mengukuhkan 
posisinya. Salah satunya adalah dari golongan agamawan Buddhis. Itulah alasan mengapa Balitung mengeluarkan keputusan untuk menjadikan seluruh vihāra berstatus swatantra. Usaha untuk memperoleh dukungan golongan agamawan seperti dilakukan Balitung mempunyai alasan yang kuat, karena golongan agamawan mempunyai kekuatan mempengaruhi masyarakat termasuk untuk mendukung Dyah Balitung. Apa pun alasan di balik pemberian anugrah sima tersebut, hal yang penting untuk diperhatikan adalah bahwa seorang raja Hindu tetap mempunyai kewajiban memperhatikan rakyatnya, meskipun rakyatnya menganut Buddhisme. Tindakan ini tentu merupakan contoh yang baik kepada rakyatnya untuk saling menghormati antara penganut kepercayaan yang berbeda. Selain itu, pemberian anugrah sima tersebut juga menjamin rakyat dari golongan kepercayaan yang berbeda tidak saling bermusuhan karena mendapat perhatian yang sama dari rajanya.

Bukti toleransi lainnya dapat dirunut melalui kutipan prasasti Salimar IV $880 \mathrm{M}$ dan prasasti Wurudu Kidul A 922 M. Kutipan prasasti Salimar IV 880 menyebutkan, "...rāmanta i kandang...marhyang si brahma. si piba. si ranu. si wala. marhyang $i$ patahun si [jabung] bihāra swāmi si tiruan si tarā." (Darmosoetopo 1971, 26). Kutipan tersebut memberikan keterangan bahwa di Wanua Kandang terdapat bangunan keagamaan Śivaistis dan vihāra, dibuktikan dengan adanya jabatan marhyang dan bihāra swāmi dalam daftar rāmanta iKandang. Baris b.3 prasasti Wurudu Kidul A 922 M menyebutkan, “...mwan rāmanta $i$ halaran san pasuk wanwa grāma vihāra kabikuan..." (Boechari 1985, 121). Kalimat tersebut menggambarkan bahwa di Wanua Halaran terdapat vihāra dan kabikuan. Kabikuan adalah tempat tinggal para biku (Zoetmoelder 2004). menarik bahwa vihāra yang bersifat Buddhis dapat berdampingan dalam satu wilayah wanua dengan kabikuan yang bersifat Hindu. Oleh karena itu, dapat diasumsikan pula bahwa penduduk di Wanua Halaran terdiri dari penganut Hindu dan Buddha, dan mereka dapat hidup berdampingan di satu wanua.

\section{PENUTUP}

Agama Buddha merupakan salah satu agama penting pada masa Jawa Kuna. Candi-candi megah seperti Borobudur, Mendut, dan Kalasan adalah bukti nyata kebesaran agama Buddha di masa lalu. Berdasarkan penelitian terhadap data prasasti, diperoleh pengetahuan tentang bangunan keagamaan Buddha lainnya yaitu vihāra. Sejauh ini belum banyak informasi tentang vihāra pada masa Jawa Kuna karena sedikitnya data monumen yang masih dapat dijumpai. Padahal, vihāra juga memiliki fungsi dan peran yang penting dalam masyarakat masa itu. Vihāra adalah tempat tinggal para bhiksu yang selain sebagai pemuka agama juga dikenal sebagai golongan terpelajar. Para bhiksu selain menjadi tokoh religius dalam masyarakat juga memegang peranan penting dalam kehidupan sosial, politik, dan ekonomi masyarakat.

Data prasasti telah menunjukkan bahwa vihāra mengalami proses pertumbuhan dan penurunan dalam hal jumlah pada kurun waktu abad VIII - XI M. Selama proses dinamika tersebut vihāra telah menunjukkan tentang bentuk-bentuk toleransi beragama antara umat beragama Hindu dan 
Buddha. Vihāra dapat hidup berdampingan dalam sebuah desa dengan para penganut agama Hindu dan bersedia terlibat dengan masyarakat dalam kehidupan sosial sehari-hari. Bahkan vihāra dapat menembus birokrasi pemerintahan hingga mampu memperoleh anugrah dari raja dan para bangsawan berupa status tanah sima, anugrah yang prestisius pada saat itu, bahkan dari raja yang beragama Hindu sekalipun. Sesungguhnya pola serupa terus berlanjut ketika para ulama menduduki peran penting pada masa kejayaan Kerajaan-kerajaan Islam di Indonesia, bahkan hingga periode pasca kemerdekaan ketika para pemuka agama masih memegang peranan penting di pemerintahan.

Bentuk-bentuk toleransi pada masa Jawa Kuna yang terekam melalui fungsi dan peran vihāra tersebut telah menunjukkan bahwa pluralisme pada masyarakat Jawa Kuna bukan menjadi pencetus konflik. Raja dan petinggi kerajaan pada masa itu menempatkan para agamawan pada posisi yang penting dalam berbagai aspek kehidupan masyarakat dan masing-masing agama dapat hidup berdampingan. Nilai-nilai luhur yang diwariskan oleh nenek moyang ini seharusnya terus dipelihara oleh bangsa Indonesia agar dapat memandang pluralisme sebagai sebuah karakter bangsa dan bukan sebagai perbedaan yang dapat memisahkan.

\section{UCAPAN TERIMA KASIH}

Penulis mengucapkan terima kasih kepada Drs. Slamet Pinardi, M.Hum dan Dra. D.S. Nugrahani selaku pembimbing skripsi. Ucapan terima kasih juga disampaikan kepada Erwiza Erman, M.A., PhD atas bantuan dan bimbingannya sehingga penulis dapat menyajikan tulisan ini dalam bentuk artikel yang baik, serta kepada E. Edward McKinnon atas masukannya dalam penyempurnaan artikel ini. 


\section{DAFTAR PUSTAKA}

Brandes, J.L.A. 1913. 'Oud Javaansche Oorkonden, Nagelaten Transcripties". VBG LX. Batavia : Albrecht \& Co.

Boechari. 1985. Prasasti Koleksi Museum Nasional Jilid 1. Jakarta : Proyek Pengembangan Museum Nasional.

de Casparis, J.G. 1956. Selected Inscriptions From The 7th to The 9th CenturyA.D. (Prasasti Indonesia II). Bandung : Masa Baru.

Christie, Jan Wisseman. 2000. Register of The Inscription of Java Part 1: 732 to898 A.D.

855 - May 898 A.D.

2002. Register of The Inscriptions of Java Part 2: May

898 - May 929 A.D

2004. Register of The Inscriptions of Java Part 3: May

Chodron, Thubten. 1995. Tradisi dan Harmoni: Menelusuri Jejak-jejak Agama Budha. Bandung: Yayasan Penerbit Kanariya.

Damais, L.C. 1952. 'Études D’épigraphie Indonésienne. III - Liste Des Principales Inscriptions Datées de L'Indonésie'. Dalam BEFEO Tome XLVI

1995. 'Agama Budha di Indonesia'. Epigrafi dan Sejarah Nusantara: Pilihan Karangan Louis-Charles Damais. Jakarta: EFEO.

Darmosoetopo, Riboet. 1971. Prasasti Salimar IV. Skripsi Sarjana. Yogyakarta: Fakultas Sastra dan Kebudayaan Univeristas Gadjah Mada.

IXXTU. Yogyakarta: Prana Pena.

2003. Sima dan Bangunan Keagamaan di Jawa Abad

Degroot, Véronique. 2006. 'The Archaeological Remains of Ratuboko : From Sri Lankan Buddhism to Hinduism'. Dalam Indonesia and The Malay WorldVol. 34 No. $98: 55-74$.

Griffiths, Arlo. 2014. 'Early Indic Inscriptions of Southeast Asia'. Dalam Lost Kingdoms: Hindu-Buddhist Sculpture of Early Southeast Asia. New York: Metropolitan Museum of Art. HIm 53-57

Groeneveldt, W.P. 1960. Historical Notes on Indonesia and Malaya Compiled From Chinese Sources. Jakarta : C.V. Bhratara

Guy, John. 2014. 'Introducing Early Southeast Asia'. Dalam Lost Kingdoms: Hindu-Buddhist Sculpture of Early Southeast Asia. New York: Metropolitan Museum of Art. HIm. 3-13 
Indradjaja, Agustijanto. 2005. 'Awal Persentuhan Agama Buddha di Daerah Pantai Utara Jawa Barat (Kompleks Percandian Batujaya)'. Dalam Religi dalam Dinamika Masyarakat : 45-59.

Kandahjaya, Hudaya. 2004. 'A Study of The Origin and Significance of Borobudur'. Disertasi. California : Berkeley University.

Kompas.com. 2013. Terduga Pelaku Peledakan Vihara Ekayana Ditangkap. (http://nasional.kompas.com/read/2013/12/16/1219099/Terduga.Pelaku.Pel edakan.Vihara.Ekayana.Ditangkap, diakses tanggal 1 November 2014)

Kompas.com. 2014. Mengapa Teroris Incar Wihara? (http://nasional.kompas.com/read/2014/01/02/1950588/Mengapa.Teroris.In car.Wihara. diakses tanggal 6 November 2014)

Kusen. 1989. 'Faktor-faktor Penyebab Terjadinya Perubahan Status Sawah di Wanua Tengah Dalam Masa Pemerintahan Raja-Raja Mataram Kuna Abad8-10'. Laporan Penelitian. Yogyakarta: Fakultas Sastra Universitas Gadjah Mada.

Louis, Frederic. 1995. Buddhism. Paris: Flammarion.

Manguin, Pierre-Yves dan Agustijanto Indradjaja. 2011. 'The Batujaya Site: New Evidence of Early Indian Influence in West Java'. Dalam Pierre-Yves Manguin, A. Mani dan Geoff Wade (ed.)

Early Interactions Between South and Southeast Asia: Reflections on Cross Cultural Exchange. Singapore: Institute of Southeast Asian Studies.

Miksic, John N. 1994. 'Double Meditation Platforms at Anuradhapura and The Pendopo of Ratu Boko'. Dalam Saraswati : Esai-esai Arkeologi 2.KALPATARU Majalah Arkeologi No. 10 : 23-31. Jakarta : Puslitarkenas.

Mochtar, Agni Sesaria. 2009. 'Vihara Pada Masa Jawa Kuna Abad VIII-XI M (Tinjauan Data Prasasti)'. SKRIPSI SARJANA. Yogyakarta. Fakultas IImu Budaya-Universitas Gadjah Mada.

Pinardi, Slamet. 1984. 'Data Sementara Bangunan Kompleks Pendapa Kraton Ratu Baka'. Dalam Berkala Arkeologi V (2). Yogyakarta : Balai Arkeologi Yogyakarta.

Prajudi, Rahadhian. 1999. Kajian Tipo-Morfologi Arsitektur Candi di Jawa. Tesis Magister Program Studi Arsitektur. Bandung: Program Pasca Sarjana Institut Teknologi Bandung.

Robinson, Richard dan Willard Johnson. 1977. The Buddhist Religion: a Historical Introduction Second Edition. Massachusetts: Duxbury Press.

Sankalia, Hasmukh D. 1934. The University of Nalanda. Madras : B.G. Paul \&Co. 
Sarkar, Himanshu Bhusan. Sarkar, Himansu Bhusan. 1972. Corpus of The Inscriptions of Java : Corpus Inscriptionum Javanicarium up to 928 A.D. Calcuta : Firma K.L.Mukhopadhyay.

Soekmono. 1973. Sejarah Kebudayaan Indonesia Jilid II. Jakarta: Penerbit Kanisius.

1974. 'Candi: Fungsi dan Pengertiannya'. Disertasi. Jakarta: Fakultas Sastra Universitas Indonesia

Soetanti, Ninie. 1996. 'Analisis Prasasti'. Dalam PIA VII : 171-182. Jakarta: Puslitarkenas.

Sudjangi, H. 2002. Konflik Sosial Bernuansa Agama: Studi Kasus Kerusuhan di Ambon. Laporan Penelitian, Pusat Penelitian dan Pengembangan Kehidupan Beragama. Jakarta: Departemen Agama.

Sunberg, Jeffrey Roger. 2004. 'The Wilderness Monks of The Abhayagirivihāra and The Origins of Sino-Javanese esoteric Buddhism'. Dalam BKI CLX-I : 95-123. Koninklijk Instituut voor Taal-, Land- en Volkenkunde.

Tim Puslitbang Kehidupan Beragama. 2006. Studi Model Alternatif Penyelesaian Konflik Kasus Padang Sappa Kabupaten Luwu Provinsi Sulawesi Selatan. Laporan Penelitian, Pusat Penelitian dan Pengembangan Kehidupan Beragama. Jakarta: Departemen Agama.

Tim Peneliti. 2001. Hubungan Antar Agama: Sebuah Analisis Sosial Keagamaan. Laporan Penelitian, Pusat Penelitian dan Pengembangan Agama dan Diklat Keagamaan. Yogyakarta: UIN Sunan Kalijaga.

Utomo, Bambang Budi. 2007. 'Budha dan Sangha di Nusantara Pada Abad ke-913 M.' Dalam Archaeology Goes to Mall, Jejak Peradaban Nusantara Abad 9 Sampai Dengan 13. Maha Karmawibhangga: Warisan Tersembunyi di Kaki Borobudur : 10-23. Jakarta : Puslitarkenas.

Zoetmoelder, P.J. 2004. Kamus Jawa Kuna-Indonesia. Jakarta : PT. Gramedia. 